\title{
Stability of wide-graded granular filters under oscillatory flow
}

\author{
D. Schürenkamp \& H. Oumeraci \\ Technische Universität Braunschweig, Leichtweiß-Institute for Hydraulic Engineering and Water Resources \\ (LWI), Braunschweig, Germany
}

J. Kayser

Federal Waterways Engineering and Research Institute (BAW), Karlsruhe, Germany

\begin{abstract}
Granular filters are applied for bed and bank protections and installed at coastal and offshore structures (i) to prevent erosion and (local) liquefaction, (ii) to avoid sinking and sagging of the cover layer into the subsoil, and (iii) to provide a sufficient superimposed load to the subsoil countering failure due to excess pore pressure. Offshore and coastal structures are mainly subject to oscillatory flow driven by windinduced waves. Geotechnical and hydraulic processes are studied and discussed with the key objective of developing hydraulic filter criteria for granular filters in marine environments. The focus of this paper is on the contact erosion at the interface of a wide-graded granular filter and subsoil subject to oscillatory flow perpendicular to the interface. For this purpose, a new test facility is applied for the first time and a new test cell is developed.
\end{abstract}

\section{INTRODUCTION}

\subsection{Motivation}

Offshore and coastal structures are under the influence of oscillatory flow driven by wind-induced waves. Granular filters are applied in bed and bank protections and installed at coastal and offshore structures to provide sufficient resistance against the impact of waves and currents. The failure of these marine structures is, in many cases, assigned to the lack of filter stability particularly associated with contact erosion. Besides contact erosion driven by hydraulic loads and stresses of the protected soil layers, internal instability through critical hydraulic loads and the susceptibility of wide-graded granular filters are key processes of the filter design (Shire, 2014). The focus of this paper is on the contact erosion at the interface of a granular filter and subsoil of a horizontal seabed under oscillatory flow perpendicular to the interface.

\subsection{Objectives}

The objectives of the ongoing research project (DFG Ou 1/16-1) are (i) improvement of the understanding of hydro-geotechnical processes, (ii) assessment of the hydraulic gradient as a reference of the hydraulic filter stability and (iii) development of generic design formulae for the hydraulic filter stability. The understanding of the hydro-geotechnical processes underlying filter stability and the threshold values of the filter stability in terms of equivalent critical wave parameters are the focus of this paper. Concerning this, these processes including grain motion, layer mixing and subsidence as the result of contact erosion and internal erosion are the key aspects. The understanding of these processes is the objective for the final development of hydraulic filter criteria for granular filters in marine environments.

\subsection{Methodology}

In order to study the hydraulic and hydrogeotechnical processes of granular filters a test setup is developed. For this purpose, the new alternating flow facility (at the Federal Waterways Engineering and Research Institute (BAW) in Karlsruhe, Germany) is applied for the first time and a new test cell is designed, constructed and deployed for the hydraulic filter tests. The experimental setup consists of a gravel filter layer placed on a sand layer and subject to an oscillatory flow perpendicular to the interface of these layers. The hydraulic load is increased stepwise during the test series while the movement and vertical displacement of the base and filter layer are observed. At the same, time the pore pressure in the cell centre in different layers and the filter velocity at the inlet and outlet of the test cell are measured. With these hydraulic parameters, the hydraulic behaviour is analysed for each filter configuration with different geotechnical parameters. Before and after each test series, the grain size distribution of the filter material in several layers is determined by sieve analysis. 


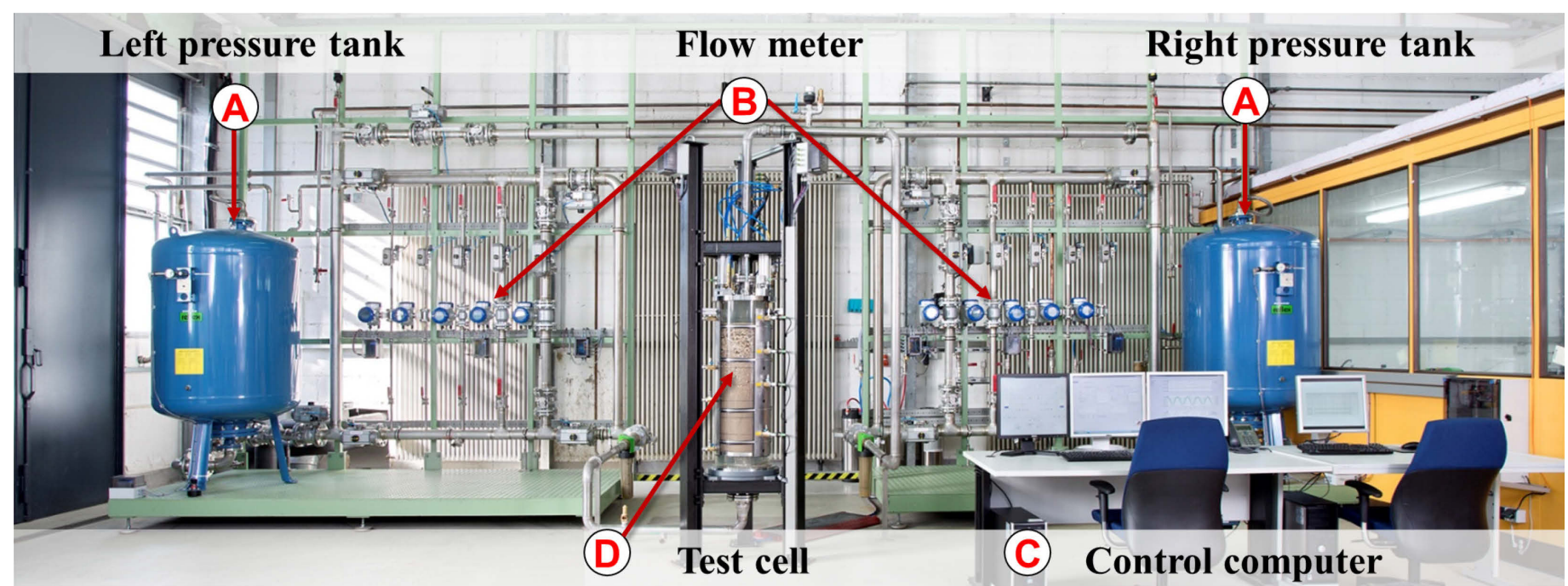

Figure 1. Oscillatory flow facility at the Federal Waterways Engineering and Research Institute in Karlsruhe (modified after Kayser et al., in press).

The hydro-geotechnical behaviour and the temporal changes in the geotechnical parameters of the filter are studied. The stability of the filter can finally be classified into stable, unstable or semi-stable conditions. This includes the hydraulic threshold values at the time of the incipient motion due to contact erosion.

The analysis of the hydraulic filter tests is focused on the following key aspects (i) the hydraulic behaviour of stable filters without particle movement, (ii) the hydraulic gradient as a function of equivalent wave parameters, (iii) comparison of the hydraulic behaviour of stable and unstable conditions (iv) determination of the hydro-geotechnical parameters including permeability and relation between hydraulic gradient and filter velocity and the associated dynamics, (v) grain motion, vertical displacement and layer mixing as a result of erosion processes and (vi) comparison of the hydro-geotechnical behaviour of filters under unidirectional and oscillatory flow. A special experimental setup is therefore developed and precise measuring and analysis techniques are applied, as specified in the following chapter.

\section{EXPERIMENTAL SETUP}

\subsection{Alternating flow facility}

The study of the hydro-geotechnical processes of granular filters is performed with a new test facility. The alternating flow facility is developed at the Federal Waterways Engineering and Research Institute (BAW) in Karlsruhe based on the experience gained from previous investigations of Köhler (1993). The test facility is equipped, calibrated and applied for the first time in this research project. Figure 1 shows a photo of the test facility with the main components (A) pressure tanks, (B) flow meter, (C) control computer and (D) test cell.
The key advantages of this facility are the adaptability for different test cells, the generation of high pressure up to 9 bar, the high accuracy of measurement and control devices, the potential of fast changing pressures up to $0.5 \mathrm{bar} / \mathrm{s}\left(\approx 5 \mathrm{mH}_{2} \mathrm{O} / \mathrm{s}\right)$ and the possibility to generate predefined pressure time series of different patterns, for instance irregular time series in place of natural sea states (Kayser et al., in press).

A new test cell is developed for the use in the oscillatory flow facility especially for wide-graded granular filters with a grain size up to $30 \mathrm{~mm}$. The arranged test cell is shown in Figure 2 including a definition sketch and a photograph.

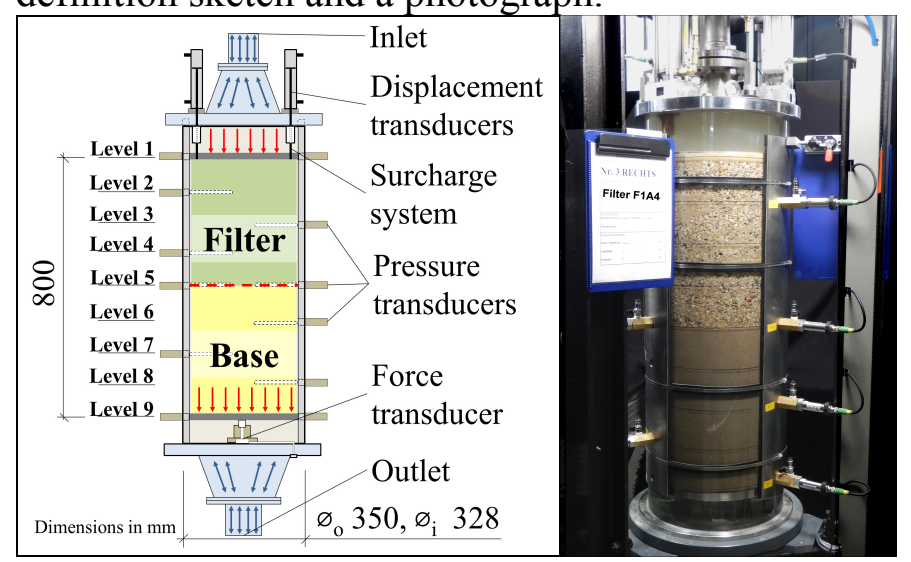

a) Sketch of the test cell with levels.

b) Photo of the test cell.

Figure 2. Definition sketch and photo of the arranged test cell with measuring and control devices (dimensions in $\mathrm{mm}$ ).

The following requirements are met with the new test cell: (i) measurement of pore pressure in the cell centre, (ii) measurement of the filter velocity at the cell inlet and outlet, (iii) monitoring of the vertical filter displacement, (iv) measurement of the imposed load at the top of the filter, and (v) measurement of the stress at the bottom of the test specimen. Therefore, the cell and the facility are equipped with highprecision pressure transducers, flow meters adapted for different measuring ranges, high-definition video 
cameras, inductive displacement transducers and a special waterproof force transducer.

\subsection{Test Programme}

In the context of wind-induced water waves, present in offshore environment, significant hydraulic parameters are determined for three different water depths $d=5 \mathrm{~m}, 25 \mathrm{~m}$ and $45 \mathrm{~m}$. The hydraulic load, based on equivalent wave parameters (in relation to waves with a free water surface), is increased incrementally up to an equivalent maximum wave height $H$. The maximum wave height $H$ is dependent on the water depth $d$ (not to be confused with the grain size, e.g. $d_{15 F}$, since the water depth $d$ is declared in this paper without indices). The maximum wave height is determined for near-breaking waves and therefore related to water depth $d$ with $H / d \leq 0.78$ (breaker index) after McCowan (1891) and to the wave length $L$ by the maximum wave steepness $H / L \leq 0.142$, dependent on the water depth $d$ after Miche (1944).

A new approach based on linear wave theory is developed for the determination of the pressure amplitude $a_{p}$ and the frequency $f$, controlled in the oscillatory flow facility. Figure 3 shows the approach, starting with the maximum breaker index $H / d=0.78$ in a relevant range of water depth $d$ (here: $5 \mathrm{~m}<d<45 \mathrm{~m})$ and maximum wave steepness $H / L=0.142$. The wave period $T$ (or frequency $f$ ) is determined based on the water depths $d$ and wave length $L$. In the next step, the pressure $p_{\text {bed }}$ at the seabed is calculated according to linear wave theory (Dean \& Dalrymple, 1991). During the test the time series are recorded using a sampling rate of $100 \mathrm{~Hz}$. These time series are analysed and the achieved equivalent wave parameters are determined with the use of the reversed pressure formula according to the linear wave theory (Figure 3).

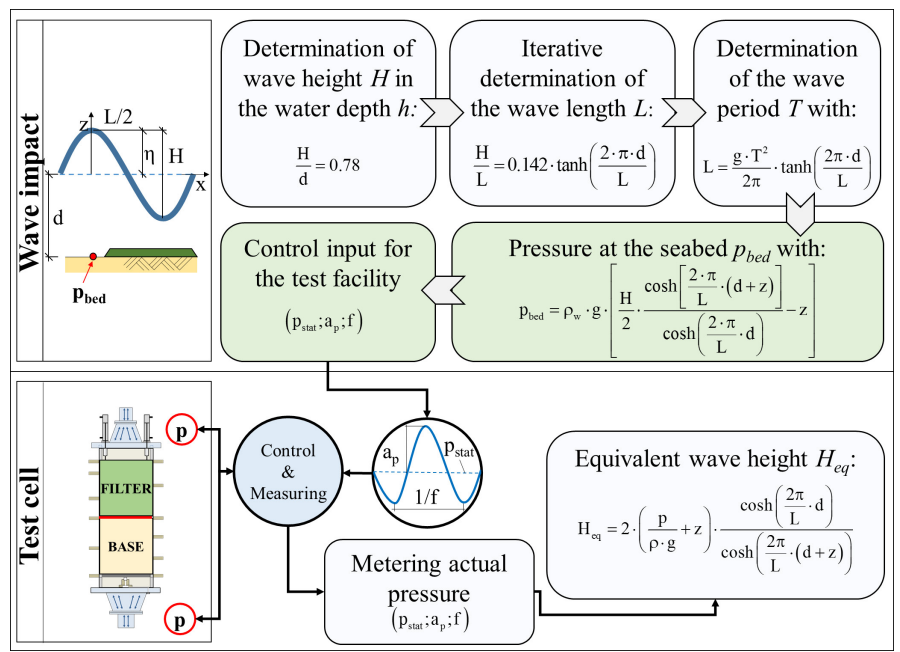

Figure 3. Approach for the determination of control inputs of the test facility (in Figure 1) based on the linear wave theory.

\subsubsection{Hydraulic parameters}

The main test programme listed in Table 1 is performed for various filter types (see section 2.2.2 and Table 2) with an equivalent water depth of $d=25 \mathrm{~m}$. These tests were repeated for water depths $d=5 \mathrm{~m}$ and $45 \mathrm{~m}$. Besides the main tests, additional tests are performed in order to achieve intermediate values of the breaker index $H / d$ and the wave steepness $H / L$.

Table 1. Main test programme for the filter in Table 2.

\begin{tabular}{lccc}
\hline Breaker index $H / d$ & 0.78 & 0.45 & 0.30 \\
\cline { 2 - 4 } Wave steepness $H / L$ & & & \\
\hline 0.142 & $\mathrm{o}$ & $\mathrm{x}$ & - \\
0.090 & $\mathrm{x}$ & $\mathrm{x}$ & $\mathrm{o}$ \\
0.080 & $\mathrm{x}$ & $\mathrm{x}$ & $\mathrm{o}$ \\
\hline
\end{tabular}

([x] main tests, [o] additional tests).

The hydraulic gradient is increased stepwise by increasing the equivalent wave height $H$ and wave frequency $f$ until the incipient motion of the base material at the filter interface is approximately reached and in some cases up to critical unstable conditions.

\subsubsection{Geotechnical and geometrical parameters}

Different filter gradations are studied with coefficients of uniformity $\left(\mathrm{C}_{\mathrm{U}}\right)$ in a range of $2.3<C_{U}<6.6$ (at initial state) and with an initial filter-base ratio of $2.3<d_{15 F} / d_{85 B}<19.9$. The test programme is performed with four filter types F1A, F1B, F1C and F2A, shown with the grain size distribution in Figure 4. Filter type F1A is repeatedly tested in three test series F1A1, F1A2 and F1A3 and the filter type F2A was tested with two test series F2A1 and F2A2 under different hydraulic conditions and to ensure repeatability. The slight variation of the geotechnical parameters and grain size distribution occurred due to deviations in weighing, mixing, sampling and sieving of the filter material.

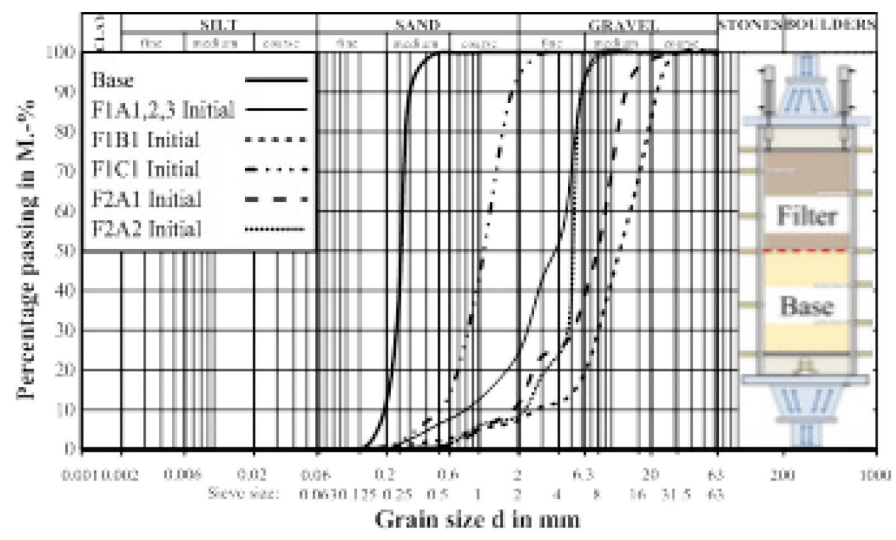

Figure 4. Grain size distribution of the specimen at initial state.

The superimposed load at the top of the filter is determined with $p_{\text {load }}=30 \mathrm{kN} / \mathrm{m}^{2}$, in place of the dead load of a cover layer. Further studies are realised with a superimposed load of $p_{\text {load }}=5 \mathrm{kN} / \mathrm{m}^{2}$ and $15 \mathrm{kN} / \mathrm{m}^{2}$. Table 2 outlines the main parameters of the base and filter material applied in the hydraulic 
experiments. The test series are performed for four filter types (F1A, F1B, F1C and F2A) with overall seven filter configurations (identified by the suffix 1 , 2 or 3 ).

Table 2. Geotechnical parameters of base and filter material at initial state*.

\begin{tabular}{lrrrrrrr}
\hline & $d_{15 F} / d_{85 B}$ & $d_{15 F} / d_{50 B}$ & $d_{15}$ & $d_{50}$ & $d_{85}$ & $C_{U}$ & $C_{C}$ \\
& \multicolumn{1}{c}{} & & & & & & \\
\cline { 2 - 8 } & \multicolumn{1}{c}{} & - & $\mathrm{mm}$ & $\mathrm{mm}$ & $\mathrm{mm}$ & - & - \\
\hline Base & - & - & 0.21 & 0.25 & 0.27 & 1.3 & 1.2 \\
F1A1 & 4.5 & 4.8 & 1.20 & 3.73 & 5.65 & 5.9 & 1.5 \\
F1A2 & 4.5 & 4.8 & 1.20 & 3.73 & 5.65 & 5.9 & 1.5 \\
F1A3 & 4.3 & 4.6 & 1.15 & 4.85 & 4.99 & 6.6 & 1.9 \\
F1B1 & 19.9 & 21.3 & 5.36 & 12.17 & 18.03 & 5.5 & 1.7 \\
F1C1 & 2.3 & 2.4 & 0.61 & 1.07 & 1.64 & 2.3 & 1.2 \\
F2A1 & 8.3 & 8.9 & 2.24 & 7.84 & 10.89 & 4.8 & 1.7 \\
F2A2 & 9.9 & 10.5 & 2.65 & 5.57 & 5.61 & 2.5 & 1.9 \\
\hline
\end{tabular}

* The geotechnical parameters deviate from the initial state in case of contact erosion or internal erosion.

$C_{U}=d_{60} / d_{10}$, coefficient of uniformity;

$C_{C}=d_{30}^{2} /\left(d_{60} \cdot d_{10}\right)$, coefficient of curvature.

Typical grain size distributions are selected for the filters with regard to the filter criteria after Terzaghi \& Peck (Terzaghi \& Peck, 1961) for filter F1A, F1B and F2A as well after de Graauw et al. (1983) for filter F1C. The target grain size distribution of the filter is defined by the grain size $d_{15 F}$ at $15 \%$ mass percentage passing and by the coefficient of uniformity $C_{U}$ shown in Table 2 . The different filter configurations are combined with one specific base material in all tests (see Table 2).

\section{RESULTS AND DISCUSSION}

\subsection{Hydraulic processes of stable filters}

The laboratory tests with the oscillatory flow facility provided a sufficient data basis for the analysis of hydraulic and hydro-geotechnical processes in granular filters.

At first, the focus was put only on the hydraulic conditions of the test specimen under stable conditions without any transport of base material. Therefore, each test is classified by stable, semi-stable and unstable conditions and only the test series with stable filter conditions are selected for the hydraulic analysis (shown in Figure 5). As the significant hydraulic gradient occurs in the base material (level 5) below the interface to the filter (level 6), the maximum hydraulic gradient $i_{5,6}$ is determined (see Figure 2) by the following equation:

$$
i_{a, b}=\left(\frac{p_{b}-p_{a}}{\rho_{w} \cdot g}\right) \cdot \frac{1}{\Delta l_{a, b}}
$$

where: $i_{a, b}=$ hydraulic gradient between level $a$ and level $b ; g=$ acceleration due to gravity in $\mathrm{m} / \mathrm{s}^{2}$; $\rho_{w}=$ density of the fluid in $\mathrm{kg} / \mathrm{m}^{3}$ (here: $1000 \mathrm{~kg} / \mathrm{m}^{3}$ ); $p_{a}=$ pressure (relative) at level $a$ in $\mathrm{N} / \mathrm{m}^{3}$; $p_{b}=$ pressure (relative) at level $b$ in $\mathrm{N} / \mathrm{m}^{3}$; and $\Delta \mathrm{l}=$ distance between level $a$ and level $b$.

The hydraulic gradient $i_{5,6}$ between level 5 and level 6 at the interface in the base material (see Figure 2) is analysed as a function of the wave parameters (see Figure 5).

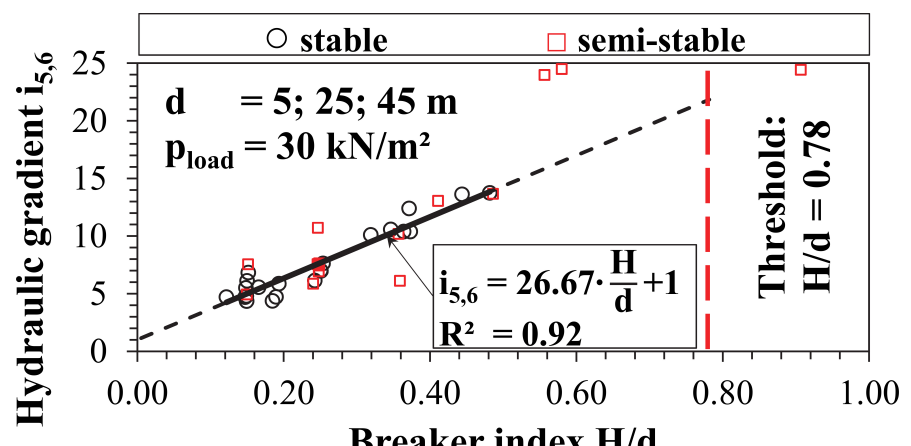

a) Hydraulic gradient $i_{5,6}$ as a function of the breaker index $H / d$.

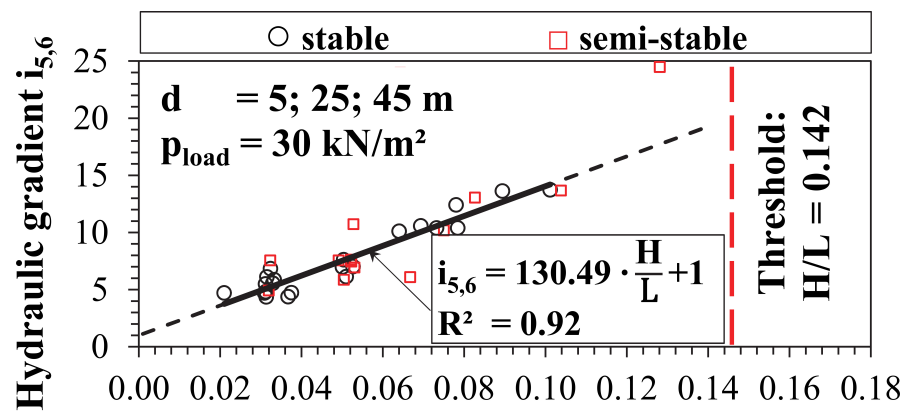

Wave steepness $\mathbf{H} / \mathbf{L}$

b) Hydraulic gradient $i_{5,6}$ as a function of the wave steepness $H / L$.

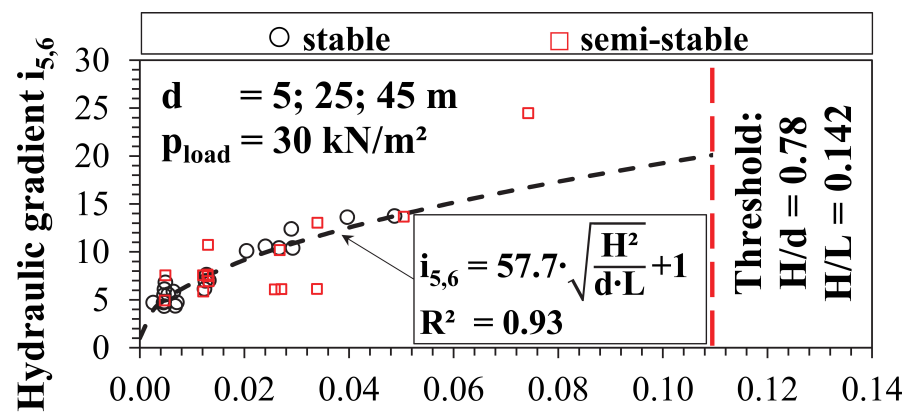

Wave parameter $\mathbf{H}^{2} /(\mathbf{d} \cdot \mathbf{L})$

c) Hydraulic gradient $i_{5,6}$ as a function of $H^{2} /(d \cdot L)$.

Figure 5. Hydraulic gradient $i_{5,6}$ as a function of wave parameters $H / d$ in a), $H / L$ in b) and $H^{2} /(d \cdot L)$ in c) under stable filter conditions. 
The tests are classified by the stability, and a good correlation is found for the hydraulic gradient of stable filter conditions with the breaker index $H / d$ (Figure $5 \mathrm{a}$ ) and with the wave steepness $H / L$ (Figure $5 \mathrm{~b})$. In addition, a good correlation exists for the hydraulic gradient with $H^{2} /(d \cdot L)$ as a product of wave steepness $H / L$ and breaker index $H / d$ (Figure 5 c) for stable filters. It becomes apparent that the wave parameter $H^{2} /(d \cdot L)$, as a function of wave height $H$, water depth $d$ and wave period $T$, is an adequate indicator for the filter stability.

Compared to stable filters, higher hydraulic gradients (between level 5 and 6) occur for semi-stable and unstable filters, if the permeability of the filter is reduced due to infiltration or clogging, and lower hydraulic gradients occur in case of increasing permeability of the filter due to local liquefaction at the interface of base and filter or internal erosion in the filter layer. The filter behaviour can be observed by the displacement of the filter top and by a shifting of the boundary between the base and filter layer. In addition, the filter stability is determined through changes in the hydraulic behaviour, identified by changes in the permeability.

The connection between wave parameters and the maximum hydraulic gradient at the interface of base and filter is the first important step for the description and assessment of the filter stability. Following this, the establishment of the relation between wave parameters and filter stability is needed. Therefore, the limits of stable and semi-stable filter conditions are shown in Figure 6 with the reached maximum of the parameter $H^{2} /(d \cdot L)$. The highest stability is achieved for filter configuration $\mathrm{F} 1 \mathrm{C} 1$, since the filter-base ratio of $d_{15 F} / d_{85 B}=2.3$ and the coefficient of uniformity $C_{U}=2.3$ are lower compared to the lowest stability of filter configuration F2A1 with $d_{15 F} / d_{85 B}=8.3$ and $C_{U}=4.8$.

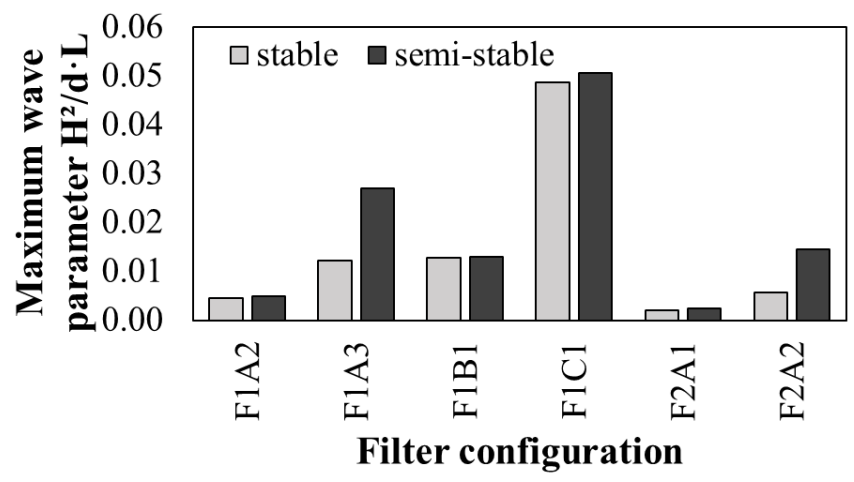

Figure 6. Maximum wave parameter $H^{2} /(d \cdot L)$ for the filter configurations for stable and semi-stable conditions.

Figure 6 shows the limits of the filters as a function of the equivalent wave parameter: wave height $H$, wave period $T$ and the water depth $d$. Beyond these limits the base material incipiently erodes at the interface and the filter is no longer statically stable. In the case of filter F1C1 no unstable but semistable conditions are achieved even though the max- imum hydraulic load of the test facility is reached $(H / d=0.91 ; H / L=0.192)$. This filter indicates a geometrically closed filter and, therefore, this case is used as a reference for the hydraulic behaviour under undisturbed conditions without particle movement.

In summary, it can be stated that the hydraulic gradient is described as a function of extreme wave conditions including the threshold values for wave steepness and breaker index. With the hydraulic behaviour shown in Figure 5 and Figure 6 the connection of wave parameters and the filter stability can be established, hereby a key result for the design of geometrically open filters is achieved.

Besides the hydraulic behaviour of stable filters, the changing of hydro-geotechnical processes need to be analysed depending on the filter stability, shown in following section, in order to describe the dynamic filter behaviour.

\subsection{Hydro-geotechnical processes depending on the filter stability}

In order to identify the incipient motion of the base material due to contact erosion and to describe the hydro-geotechnical filter dynamics, the hydraulic behaviour of the base and filter layer is analysed. Therefore, the hydraulic gradient $i_{1,5}$ between the top of the filter (level 1) and the interface of the base and filter material (level 5) is determined and compared with the filter velocity $v_{f}$. Figure 7 exemplarily shows in a) the time series of the filter velocity $v_{f}$, measured at the cell inlet, and in b) the hydraulic gradient $i_{1,5}$ under stable and unstable conditions.

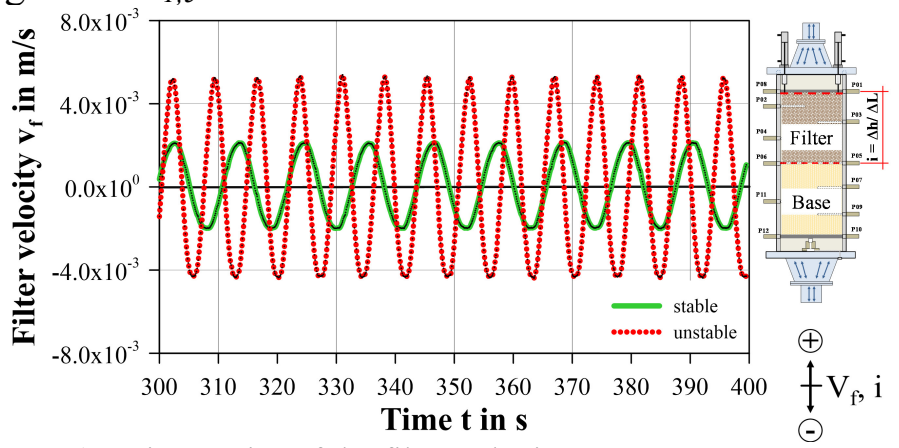

a) Time series of the filter velocity $v_{f}$.

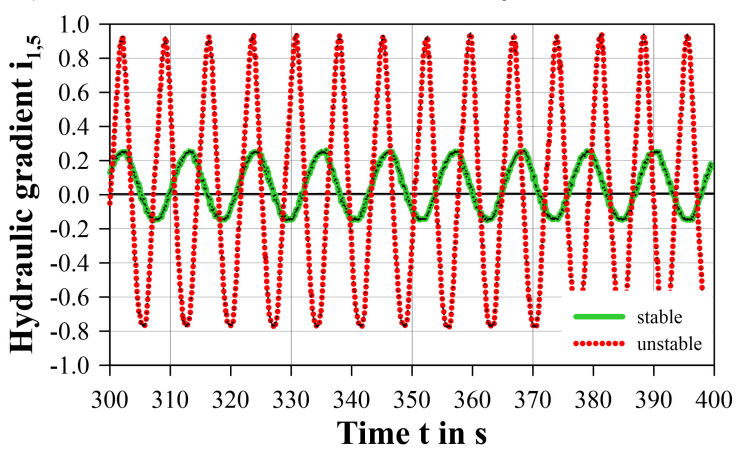

b) Time series of the hydraulic gradient $i_{1,5}$.

Figure 7. Time series of hydraulic gradient $i_{1,5}$ and filter velocity $\mathrm{v}_{\mathrm{f}}$ in comparison of stable and unstable filter conditions. stable: $\quad H=4.99 \mathrm{~m} ; T=10.99 \mathrm{~s} ; d=25.80 \mathrm{~m}$; F2A2 unstable: $H=25.94 \mathrm{~m} ; T=7.19 \mathrm{~s} ; d=25.94 \mathrm{~m} ; \mathrm{F} 2 \mathrm{~A} 2$ 
For the comparison of the filter stability, these two tests are selected. The filter velocity $v_{f}$ is plotted in comparison with the hydraulic gradient $i_{1,5}$ for stable and unstable filter conditions. It becomes apparent that, the higher the wave height $H$, the higher the filter velocity $v_{f}$ and the hydraulic gradient $i_{1,5}$.

A phase shift $\Delta t$ between filter velocity $v_{f}$ and hydraulic gradient $i_{1,5}$ occurs in the order of $\Delta t=0.2-0.4 \mathrm{~s}$. This phase shift is induced by acceleration and inertia of the water column in the oscillatory flow facility. The phase shift is considered as a constant time offset for the graphs in Figure 8 and Figure 9. Figure 8 illustrates the basic difference between stable and unstable filter conditions. The relation between the filter velocity $v_{f}$ and the hydraulic gradient $i_{1,5}$ for one pressure cycle (or equivalent wave period $T$ ) including the extreme values of wave crest and wave trough is shown in Figure 8 a). Moreover, the development of the ratio $a_{1,5}=i_{1,5} / v_{f}$ over many cycles as comparatively depicted in Figure $8 \mathrm{~b}$ ) shows the change over time under stable conditions $(H=4.99 \mathrm{~m} ; T=10.99 \mathrm{~s})$ and for unstable conditions $(H=25.94 \mathrm{~m} ; T=7.19 \mathrm{~s})$.

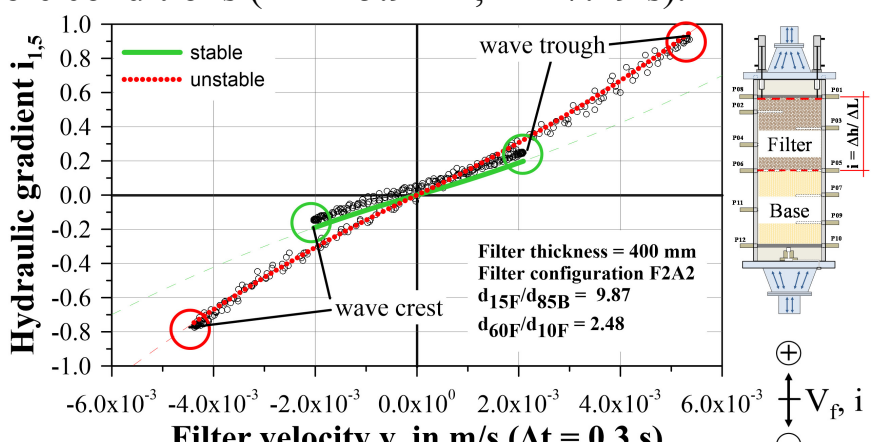

Filter velocity $v_{\mathrm{f}}$ in $\mathrm{m} / \mathrm{s}(\Delta \mathrm{t}=\mathbf{0 . 3} \mathrm{s})$

$\ominus$

a) Hydraulic gradient $i_{1,5}$ plotted over the filter velocity $v_{f}$ for one pressure cycle (or one wave period $T$ ).

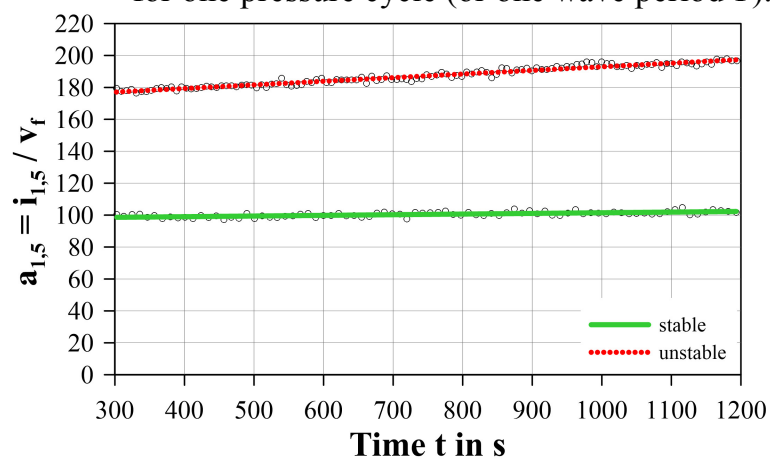

b) Time series of $a_{1,5}=i_{1,5} / v_{f}$ for stable and unstable state of the filter

Figure 8. Relation of hydraulic gradient and filter velocity stable: $\quad H=4.99 \mathrm{~m} ; T=10.99 \mathrm{~s} ; d=25.80 \mathrm{~m} ; \mathrm{F} 2 \mathrm{~A} 2$ unstable: $H=25.94 \mathrm{~m} ; T=7.19 \mathrm{~s} ; d=25.94 \mathrm{~m} ; \mathrm{F} 2 \mathrm{~A} 2$

The change of the gradient in the relation of the hydraulic gradient $i_{1,5}$ and the filter velocity $v_{f}$ can be assigned to the filling of filter pores through the transport of base material caused by contact erosion. Under stable conditions no change in $a_{1,5}=i_{1,5} / v_{f}$ can be observed compared to semi-stable and unstable conditions, where the hydraulic gradient starts to change or continuously increases. The degree of stability can be determined by the slope of the coeffi- cient $a_{1,5}$ in the time series (see Figure $8 \mathrm{~b}$ )). In case of an approximation of the coefficient $a_{1,5}$ to a steady condition (asymptotic trend), the filter is classified as semi-stable or dynamic stable, whereas a filter is classified as unstable, if the parameter $a_{1,5}$ is continually increasing. Furthermore, the parameter $a_{1,5}$ is proportional to the inverse Darcy permeability $k_{f}$, but the filter velocity in this case is measured for the flow through filter and base layer in a row.

The varying geotechnical parameters of the filter configurations (see Table 2) show a different hydraulic behaviour for a similar hydraulic load indicated by changes in the coefficients $a$ and $b$ of the Forchheimer equation:

$i_{1,5}=a \cdot v_{f}+b \cdot v_{f} \cdot\left|v_{f}\right|$

where: $i_{1,5}=$ hydraulic gradient between level 1 and 5 ; $a=$ coefficient $a$ of the laminar term in $\mathrm{s} / \mathrm{m}$; $b=$ coefficient $b$ of the turbulent term in $\mathrm{s}^{2} / \mathrm{m}^{2}$; $v_{f}=$ filter velocity (measured at the cell inlet) in $\mathrm{m} / \mathrm{s}$.

The coefficients in the equations in Figure 9 are based on the Forchheimer equation (equation 2), but the hydraulic gradient $i_{1,5}$ is related to the filter layer, whereas the filter velocity $v_{f}$ is related to the total setup of the base and filter layer. Nevertheless, the function shows the qualitative changes of the permeability dependent on the geotechnical parameters of the filter layer. These characteristics give, together with the temporal change of $a_{1,5}=i_{1,5} / v_{f}$ (Figure $8 \mathrm{~b}$ ), the key indicator for the classification in stable, semi-stable and unstable filter conditions.

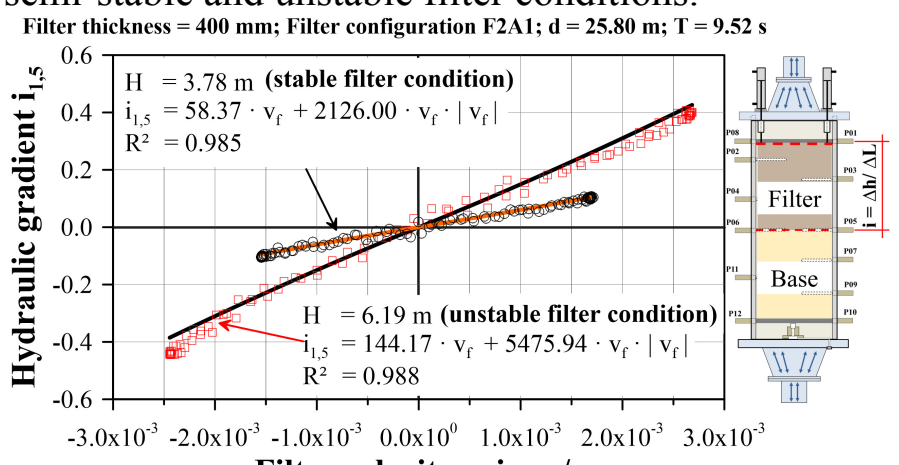

Filter velocity $\mathbf{v}_{\mathbf{f}}$ in $\mathbf{~ m} / \mathbf{s}$

a) Filter F2A1 $\left(C_{U}=4.8 ; d_{15 F} / d_{85 B}=8.3\right)$

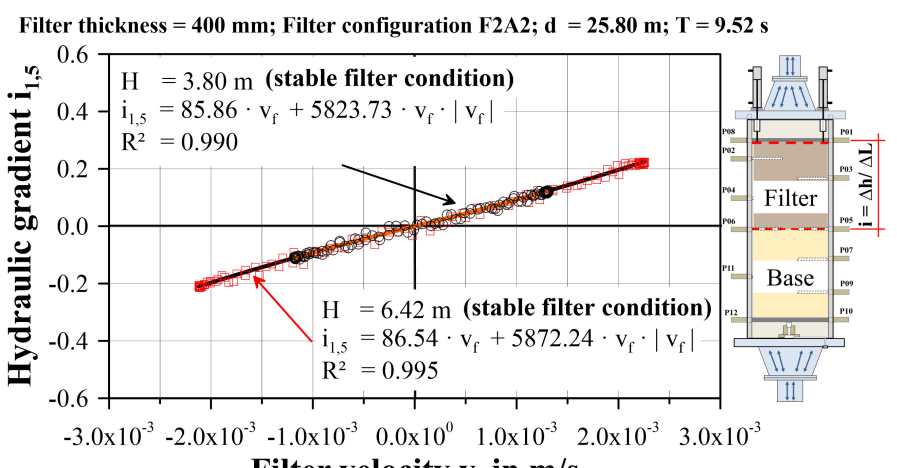

Filter velocity $\mathbf{v}_{\mathbf{f}}$ in $\mathbf{~ m} / \mathbf{s}$

b) Filter F2A2 $\left(C_{U}=2.5 ; d_{15 F} / d_{85 B}=9.9\right)$

Figure 9. Comparative plot of filter configurations F2A1 and F2A2 with filter velocity $v_{f}$ and hydraulic gradient $i_{1,5}$.

The variation and change of the hydraulic behaviour is the result of contact erosion and internal erosion, 
associated with the change of permeability, porosity and filter dimensions. Figure 9 a) and b) show a change in the hydraulic gradient $i_{1,5}$ as a function of the filter velocity $v_{f}$ for an increasing hydraulic load, whereas the hydraulic gradient in filter F2A2 is approximately constant at increasing equivalent wave height $H$, the hydraulic behaviour of filter F2A1 is temporally changing and a higher hydraulic gradient appears with the increasing hydraulic load. This process can be explained on the one hand by the nonlinear flow term and on the other hand by infiltration of base material or clogging of the filter pores, as it is analysed by displacement of the filter, grain size distribution of the filter material and by visual observation. With this approach it is possible to describe the incipient motion with contact erosion and internal erosion in terms of the changing hydraulic behaviour.

The differences between filter F2A2 and F2A1 are the coefficient of uniformity $C_{U}$ and the filter base ratio $d_{15 F} / d_{85 B}$. Whereas the filter-base ratio of F2A1 is lower compared to F2A2, the coefficient of uniformity $C_{U}$ distinguishes the hydraulic filter stability. Both, the coefficient of uniformity $C_{U}$ and the filter-base ratio $d_{15 F} / d_{85 B}$ are the governing geotechnical parameters for the stability of granular filters subject to oscillatory flow.

\subsection{Assessment of settlement and displacement of base and filter layer}

The behaviour of the specimen is visually observed by high definition video cameras from three sides around the test cell. In addition, the vertical displacement of the pressure plate at the top of the filter is measured by three inductive displacement transducers. The settlement of the filter can be measured indirectly by the vertical displacement of the top level through this approach. The vertical displacement includes the settlement as well as the compaction and mixing of the base and filter material. In Figure 10 the initial and final state of the specimen is shown for one test series.

At the beginning of each test with increasing hydraulic load an initial displacement of the filter top is observed. This effect can be assigned to a rearrangement of the load system and partly to elastic compaction of the test specimen. Dependent on the hydraulic load, the displacement is continuously increasing after exceeding the actual threshold value of the filter stability. At the same time, infiltration of fine base material in the filter pores, mixing of base and filter material, subsidence of filter grains into the subsoil and descending of the interface in consequence of contact erosion are visually observed. For semi-stable filter conditions, these processes are decelerated and in some cases unsteady under oscillatory flow. Similar processes were also observed and described by Belyashevskii et al. (1972).

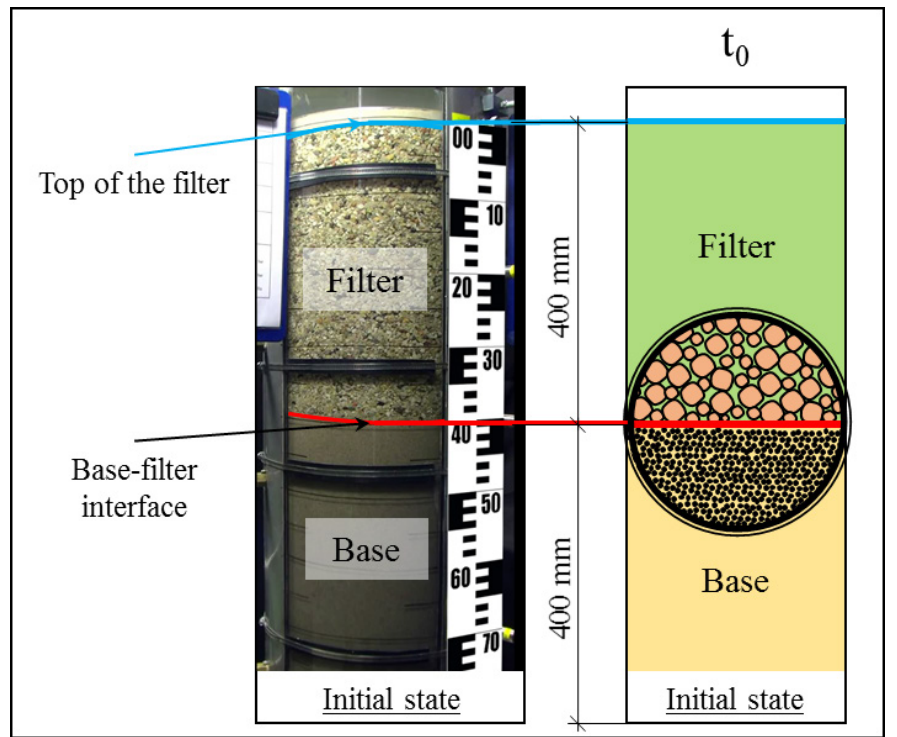

a) Base and filter layer at initial state

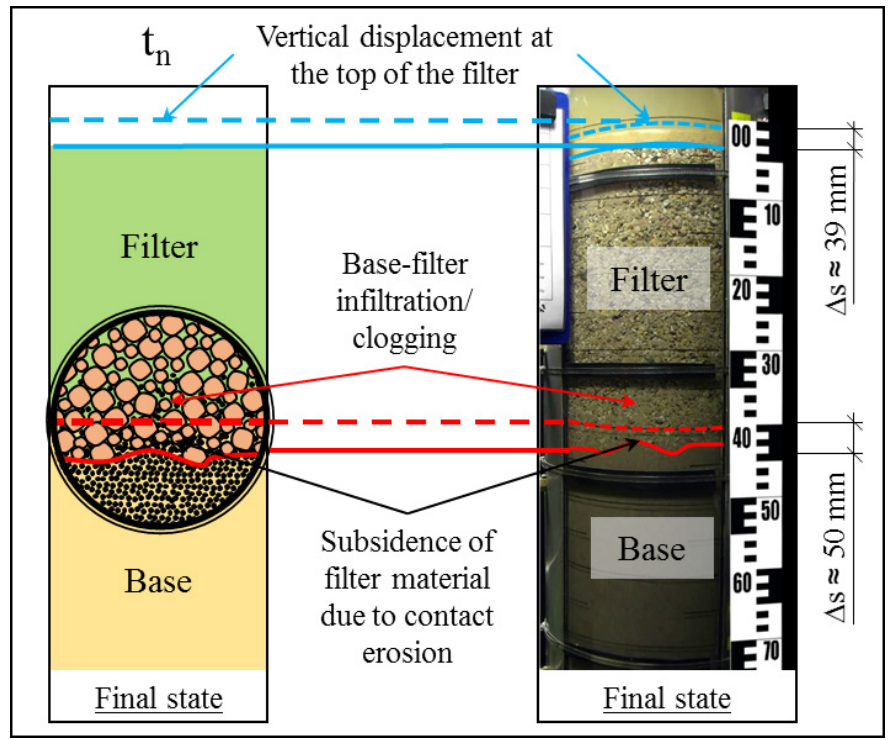

b) Base and filter layer at final state

Figure 10. Initial and final state of the test specimen in the laboratory experiments (filter configuration F1A2) showing the vertical displacement of the filter, base-filter intermixture and the caving of the filter material due to contact erosion. 
For a better classification, a sieve analysis is performed for each specimen before and after the completed test series. The mixing of the two layers by contact erosion and internal erosion in the filter layer is observed as shown in Figure 11.

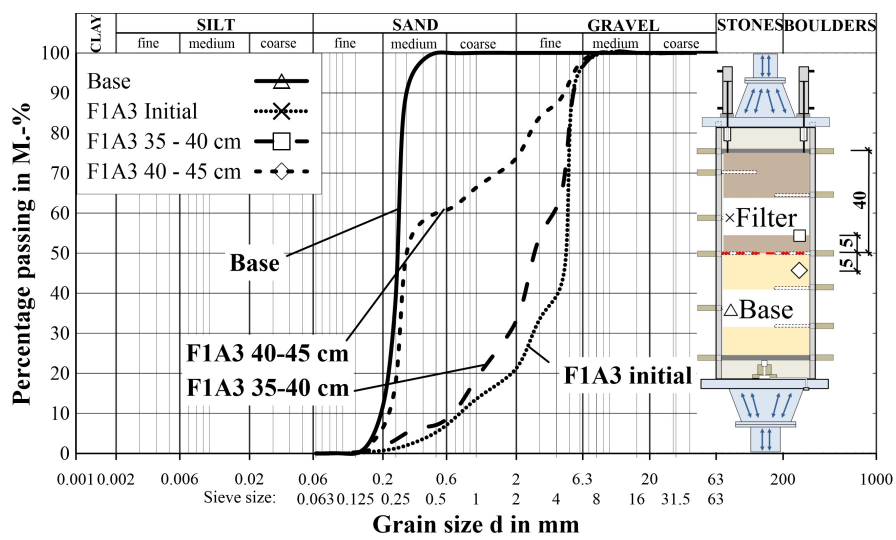

Figure 11. Grain size distribution of the individual layers of filter configuration F1A3 by sieve analysis.

The grain size distributions of the layer below and above the interface with a thickness of $5 \mathrm{~cm}$ show the mixing of base and filter material compared to the initial state of filter configuration F1A3. The content of the fine fraction increases in the filter layer and the content of the coarse fraction increases in the base layer. The sieve analysis shows the expected effect of contact erosion along with the visually observed material movement and the measured changes in the hydraulic behaviour in terms of the increasing permeability in the base layer and the decreasing permeability in the filter layer. The grain size distribution shows in addition the changes in the soil mechanics and the stress conditions. In this context, the stress transmission matrix changes by the percentage of fine fractions in the matrix. Through this effect, the dynamic filter stability increases over time due to infiltration of the base material in the pore space of the filter. This is a positive effect for the stress condition but on the other hand the internal erosion of grains in the porous matrix increases if the critical hydraulic load is reached. This leads together with the contact erosion and infiltration to a change of the total volume as observed by the vertical displacement. In the laboratory experiments a geotextile filter mat at the pressure plate on top of the filter is needed to reduce the soiling of the test facility. External suffusion cannot take place because of this model effect and the test series is finished in case the base material reaches the geotextile filter or the load system reaches the limit.

\subsection{Comparison of oscillatory and unidirectional flow}

The programme of the laboratory experiments with the oscillatory flow facility included the comparison of oscillatory and unidirectional flow. The objective is the improvement of the understanding of hydraulic and hydro-geotechnical processes of granular filters. The comparison of unidirectional and oscillatory flow is shown in Figure 12 with time series of the hydraulic gradient $i_{5,6}$ (see equation 1) in Figure 12 a) and the vertical displacement of the top of the filter in Figure $12 \mathrm{~b}$ ). In both tests a maximum hydraulic gradient of $i_{\max (5,6)} \approx 6.5$ is achieved in between layer 5 and 6 (see Figure 2).

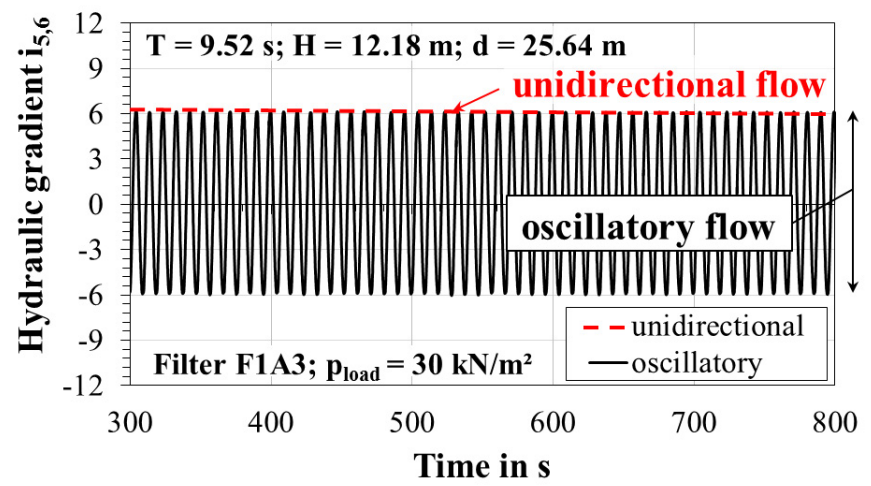

a) Hydraulic gradient $i_{5,6}$ between layer 5 and 6 .

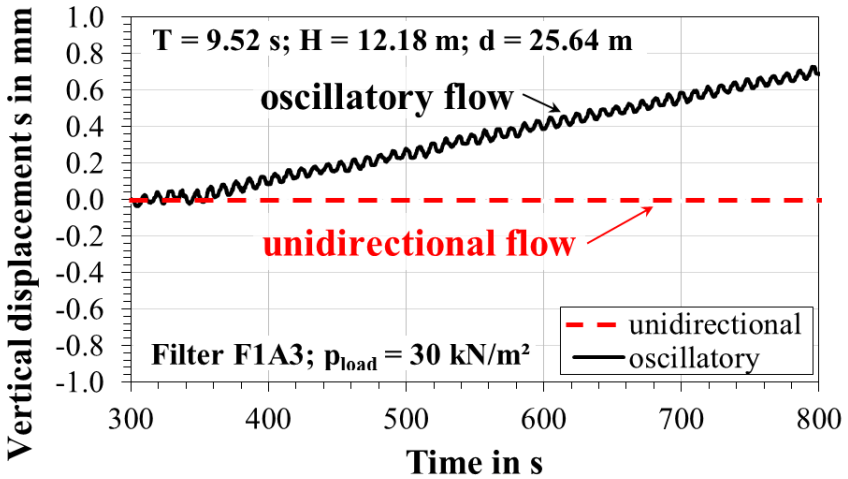

b) Vertical displacement $\mathrm{s}$ at the top of the filter.

Figure 12. Comparison of unidirectional and oscillatory flow with a) hydraulic gradient $i_{5,6}$ and b) displacement $s$ (filter configuration F1A3).

The displacement of the top of the filter (Figure 12 b)) continuously increases under oscillatory flow in contrast to unidirectional flow, where no displacement is measured. In addition, the material motion is visually observed through the transparent cell wall. It is found that contact erosion is the governing process for this displacement by comparing the grain size distribution at the initial and final state of the base and filter material (see Figure 11).

In the case of the filter configuration F1A3 (see Table 2) the filter is stable at the interface under oscillatory flow up to an equivalent breaker index of $H / d=0.24$ and an equivalent wave steepness of $H / L=0.05$. Exceeding these limits, the fine base material is incipiently eroded at an equivalent breaker index of $H / d=0.36$ and an equivalent wave steepness of $H / L=0.08$, while the filter remains statically stable under upwardly unidirectional flow at the same maximum hydraulic gradient of $i_{\max (5,6)} \approx 6.5$. Although the geometrical filter criteria for unidirectional flow $d_{15 F} / d_{85 B}=4.3<5$ after Terzaghi \& Peck 
(1961) is fulfilled, the filter is not stable under oscillatory flow.

According to former studies, the hydraulic stability of granular filters under oscillatory and unidirectional flow differs. The results are in agreement with previous studies (cf. Belyashevskii et al., 1972; Molenkamp et al., 1979; de Graauw et al., 1983; KleinBreteler et al., 1992; Köhler, 1993) in the sense that the stability of granular filters under oscillatory flow is lower compared to that under unidirectional flow. Geometrical filter criteria, developed for unidirectional flow, cannot be applied for oscillatory flow since the filter structure is affected by the cyclic pore pressure and associated effective stresses.

In addition, a lower friction between the grains occurs under oscillatory flow but a lower drag coefficient due to flow separation in the grain boundary layer reduces the flow resistance (Gent, 1992; Hall et al., 1995).

From another perspective besides the static stability of granular filters without any particle movement, an approach with semi-stable or dynamic filters is needed for filter structures subject to strong oscillatory flow. Otherwise, a lower filter ratio (like filter F1C1: $\left.d_{15 F} / d_{85 B} \leq 2.3\right)$ and a uniformity coefficient (like filter F1C1: $C_{U}=d_{60 F} / d_{10 F} \leq 2.3$ ) is needed in order to achieve a geometrically closed filter.

\section{CONCLUSIONS}

The research project was initiated for the improvement of the understanding of hydro-geotechnical processes, assessment of the hydraulic gradient as controlling factor of the hydraulic filter stability and the final development of generic design formulae for the hydraulic filter stability.

The hydraulic behaviour of stable filters was, therefore, analysed first without any particle movement in order to achieve a proper correlation of the hydraulic gradient as a function of equivalent wave parameters. This results in a function of the hydraulic gradient $i_{5,6}$ at the interface between the base and filter depending on the wave height $H$, wave length $L$ and the water depth $d$ (see Figure $6 \mathrm{c}$ )). The equivalent breaker index of $H / d$ and the equivalent wave steepness of $H / L$ combined in their product $H^{2} /(d \cdot L)$ are highly correlated to the hydraulic gradient $i_{5,6}$ of stable filter conditions.

Furthermore, the comparison of stable and unstable filter conditions showed the basic difference in the hydraulic behaviour and gives as a result of this a suitable indicator for the classification of the filter stability. The determination of the hydrogeotechnical parameters including the ratio of hydraulic gradient and filter velocity $a_{1,5}=i_{1,5} / v_{f}$ was used to classify the degree of filter stability. The associated filter dynamics in terms of grain motion, vertical displacement and layer mixing as a result of the erosion processes was described by visual observations and by sieve analyses. On this, the geotechnical and hydraulic changes caused by contact erosion, infiltration, clogging and internal erosion were illustrated.

All these hydro-geotechnical effects of the filters were discussed in comparison of unidirectional and oscillatory flow. In case of upwardly unidirectional flow, the filter remains statically stable without contact erosion $\left(d_{15 F} / d_{85 B}=4.3 ; C_{U}=6.6\right)$. Compared with oscillatory flow under the same maximum hydraulic gradient $\left(i_{\max 5,6}=6.5\right)$ the finer base material is incipiently eroded at the interface. The higher filter stability under unidirectional flow is mainly obtained by bridging of the base material at the pores of the filter material (e.g. van der Meulen, 1983 and de Graauw et al., 1983), where the finer grains of the base material clog the pores of the filter at the interface by bridging.

For granular filters exposed to strong cyclic flow, both a lower base-filter ratio $d_{15 F} / d_{85 B}$ and a lower coefficient of uniformity $C_{U}$ are needed or dynamic design approaches need to be applied.

These first results are subject to the limitations of the laboratory experiments including the damping in the base material due to the finite layer thickness, uncertainty in the gas content (saturation) and possible variations in the bulk density of base and filter layer.

Besides these specified results, further investigations are planned for the development of generic formulae for the hydraulic filter stability under oscillatory flow considering the most relevant processes and influencing factors: (i) extension and improvement of the hydraulic gradient as a function of wave parameters, (ii) improvement of the understanding of hydro-geotechnical processes of semi-stable or dynamic filters, (iii) development of theoretical models for the determination of temporal changes in the hydro-geotechnical filter characteristics as a basis for the further development of numerical models.

\section{ACKNOWLEDGEMENT}

The project "KOFIMARS" (Project No. Ou 1/16-1) is funded by the German Research Foundation (DFG). The Federal Waterways Engineering and Research Institute (BAW), Karlsruhe is cooperation partner and kindly provides the oscillatory flow testing facility. 


\section{REFERENCES}

Belyashevskii, N.N., Bugai, N.G., Kalantyrenko, I.I. \& Topchii, S.L. 1972. Behavior and selection of the composition of graded filters in the presence of a fluctuating flow: Hydrotechnical Construction. Hydrotechnical construction 6 (6), pp. 541-546. doi:10.1007/BF02377774.

de Graauw, A., van der Meulen, T. \& van der Does de Bye, M. 1983. Design criteria for granular filters. Delft Hydraulics, Delft, 25 p.

Dean, R.G. \& Dalrymple, R.A. 1991. Water wave mechanics for engineers and scientists. World Scientific, Singapore, Teaneck, NJ, xiii, 353 p.

Gent, M.R.A. van 1992. Formulae to describe porous flow. Faculty of Civil Engineering, Delft University of Technology, [Delft], $50 \mathrm{p}$.

Hall, K.R., Smith, G.M. \& Turcke, D.J. 1995. Comparison of oscillatory and stationary flow. Coastal Engineering Vol. 24, pp. 217-232.

Kayser, J., Kunz, E., Karl, F., Schürenkamp, D. \& Oumeraci, H. in press. A New Test Apparatus for Alternating Flow in Geotechnical Engineering, in: Geotechnical Testing Journal (GTJ) (Ed.). ASTM, Philadelphia, Pa.

Klein-Breteler, M., Den Adel, H. \& Koenders, M.A., 1992. Taludbekledingen van gezette steen. Ontwerpregels voor het filter.: Report M1795 / H195, part XXI. Deltares, Delft, 610 p.

Köhler, H.-J. 1993. The influence of hydraulic head and hydraulic gradient on the filtration process, in: Filters in Geotechnical and Hydraulic Engineering. Proceedings of the First International Conference 'Geo-Filter'. First International Conference 'Geo-Filter', Karlsruhe, Germany. 20.22.10.1992. CRC Press, Boca Raton, Florida, USA, p. 11.

McCowan, J. 1891. On the Solitary Wave. The London, Edinburgh and Dublin Phiosophical Magazine and Journal of Science vol. 32 (no. 5), pp. 1-45.

Miche, M.R. 1944. Mouvement ondulatoires de la mer en profondeur constante ou décroissante. 1944, pp. 25-78.

Molenkamp, F., F, C.E.O., Heusdens, J.J. \& Koenders, M.A. 1979. Cyclic filter tests in a triaxial cell, in: Proc. 7th European Conference on Soil Mechanics and Foundation Engineering. 7th European Conference on Soil Mechanics and Foundation Engineering, Brighton, pp. 97-102.

Shire, T. 2014. Micro-scale modelling of granular filters: Ph.D, $257 \mathrm{p}$.

Terzaghi, K. \& Peck, R.B. 1961. Die Bodenmechanik in der Baupraxis. Springer, Berlin [u.a.], 585 p.

van der Meulen, T., 1983. Granulaire filters: Stroming loodrecht op scheidingsvlak M 898-III. Delft Hydraulics Laboratory, Delft, $50 \mathrm{p}$. 